\title{
Expanding on the Meanings of Empathy in the Classroom: Seeing Through a Cultural Lens
}

Wayne Duncan, Angus Macfarlane, Kathleen Quinlivan and Sonja Macfarlane

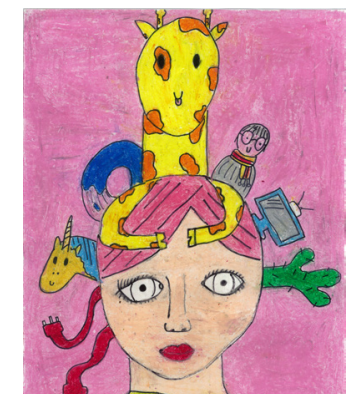

\section{ABSTRACT}

This paper explores the factors that may influence the social and relational development of empathy in a Year 13 classroom from a kaupapa Māori perspective, and discusses how these factors compare with a Western perspective of empathy. Understandings of empathy are widely documented in the conventional literature and, while the realities pertaining to empathy have been part of the fabric of Te Ao Māori (the Māori World), there has not been satisfactory levels of understanding by Western social scientists. It is proposed in this study that viewing empathy, through a bicultural lens, may provide relevant and meaningful understandings of empathy for both partners to the 1840 Treaty of Waitangi. This study explores the heuristic understandings of how the research participants experienced culturally-sensitive understandings of empathy within their face-toface classroom interactions. The understandings of 14 students and their teacher were analysed through the Māori concepts of manaakitanga, kotahitanga, rangatiratanga, whanaungatanga and pūmanawatanga; constructs that underpin Macfarlane's (2004) Educultural Wheel. Adopting a qualitative case study methodology, the participants engaged in an iterative dialogical research strategy based on Gadamer's hermeneutics (1975, 2001). This iterative research strategy enabled the students and their teacher to co-construct their developing understandings with the researcher, over time. Data collection occurred over a six-month period and comprised: 14 initial one-on-one interviews with students and the teacher; one student focus-group interview, and individual respondent-validation interviews with, respectively, 12 students and one teacher. Classroom participant observations, students' written diaries and researcher field notes enriched the interview data. Factors identified by the research participants affecting the development of empathy from kaupapa Māori perspectives are presented, and the relation to Western perspectives are discussed. The findings indicate the importance of social engagements that are founded on an ethic-of-care (manaakitanga) and are duly focused on taking an interest in the individual. The findings of the study may be helpful in informing the development of more equitable and culturally-responsive educational practices (Castagno \& Brayboy, 2008).

\section{Research paper}

Keywords:

belonging, empathy, kaupapa Māori principles

\section{PRINCIPLES OF EMPATHY RECONSIDERED}

Within a Western perspective, empathy is understood to be the ability to interpret and understand others, or to attempt to see as they see, feel as they feel, or 'be in their shoes' (Rogers, 1977; Rogers \& Freiberg, 1994). The capacity to show empathy to be able to empathise - is seen as an essential relational mechanism for effective social interaction and learning (Ickes, 1997). Empathy describes the ability of an individual to perceive another's frame of reference, enabling interpretive accuracy and, in turn, constructive responses. When successfully achieved, empathic communication continues as a back-and-forth engagement in which successful social interaction and learning can occur. Without the ability to interpret others successfully, Ickes (1997) argues, the social fabric of human interaction unravels, interpersonal engagement fails and learning is either totally lost or severely affected.

While the importance of empathy in a learning environment is a well-established construct in educational literature, it appears that not the same level of consideration has been given to linking kaupapa Māori understandings of social/ relational mechanisms to this body of knowledge. Kaupapa Māori is literally defined as 'a Māori way' and, as such, is connected to Māori principles, philosophies and practices. Māori pedagogical practices have a strong emphasis on ākonga (concurrent and reciprocal teaching and learning) and whanaungatanga (establishing relationships in a Māori context) (Macfarlane, 2004; Pere, 1991). It is not surprising, therefore, that positive classroom relationships and interpersonal engagement have 
been identified as being very important for Māori students (Bishop, Berryman \& Wearmouth, 2014; Macfarlane, 2004; Macfarlane, Cavanagh, Glynn \& Bateman, 2007).

Given the challenge of disproportionately lower academic achievement levels for Māori students, a consideration of the synergies between Māori constructs and Western notions of empathy may create an opportunity to increase understanding of the imperatives that underpin relational environments where Māori are able to succeed - as Māori. This research links understandings from some of the existing, conventional literature with kaupapa Māori concepts, and analyses input from Māori and nonMāori in a learning environment by way of a kaupapa Māori framework. It highlights culturally-responsive approaches that develop sensitivity and sensibility towards the cultural backgrounds and experiences of not only Māori students, but of all students.

It needs to be emphasised that the few kaupapa Māori principles listed above cannot alone describe a Māori perspective of empathic understanding and learning. He tirohanga Māori (a Māori worldview) has an emphasis on wholeness and the importance of the inter-relatedness of particular concepts wherein one concept cannot be fully understood in total isolation from the others. One well-established example of this is Durie's (1994) Te Whare Tapa Whā model, where holistic wellbeing comprises four domains: taha tinana (the physical domain), taha hinengaro (the psychological domain), taha whānau (the social/ relational domain), and taha wairua (the spiritual domain) - all of which are interconnected (Durie, 1984, 1994).

\section{THE EDUCULTURAL WHEEL: A CONCEPTUAL FRAMEWORK}

Two further constructs were used in the development of this study. A set of Western-identified manifestations of empathy, as acknowledged in international literature, was required as a foundation for identifying similarities in understanding empathy. This was provided by the work of Duncan (2011), which identified several manifestations of empathy relevant to this study, including, but not limited to: a sense of belonging, a strengthening bond, a supportive environment, compassion and caring, feeling as others feel, and the spontaneous spread of emotion. A kaupapa Māori overview, specific to a learning environment and relational dynamics, was required to explore the synergies and distinctions with Māori principles. This was provided by the work of Macfarlane (2004) and the Educultural Wheel. The Educultural Wheel comprises five key cultural concepts, showing their interconnections by presenting them as a wheel (see Figure 1). At the hub of the wheel is the concept of pūmanawatanga (heartbeat, pulse) which breathes life into the other four concepts. The surrounding four concepts are: whanaungatanga (building relationships, learning cooperatively); manaakitanga (the ethic of caring, creating a safe environment); rangatiratanga (teacher effectiveness and leadership, and communicating their enthusiasm to learners); and kotahitanga (the ethic of bonding, building a cohesive group dynamic, being inclusive of individuals). For Māori, and also for other indigenous cultures, the depiction of empathy includes the building of positive relationships, and asks much of those involved. This understanding is indicated in the five concepts comprising the Educultural Wheel.

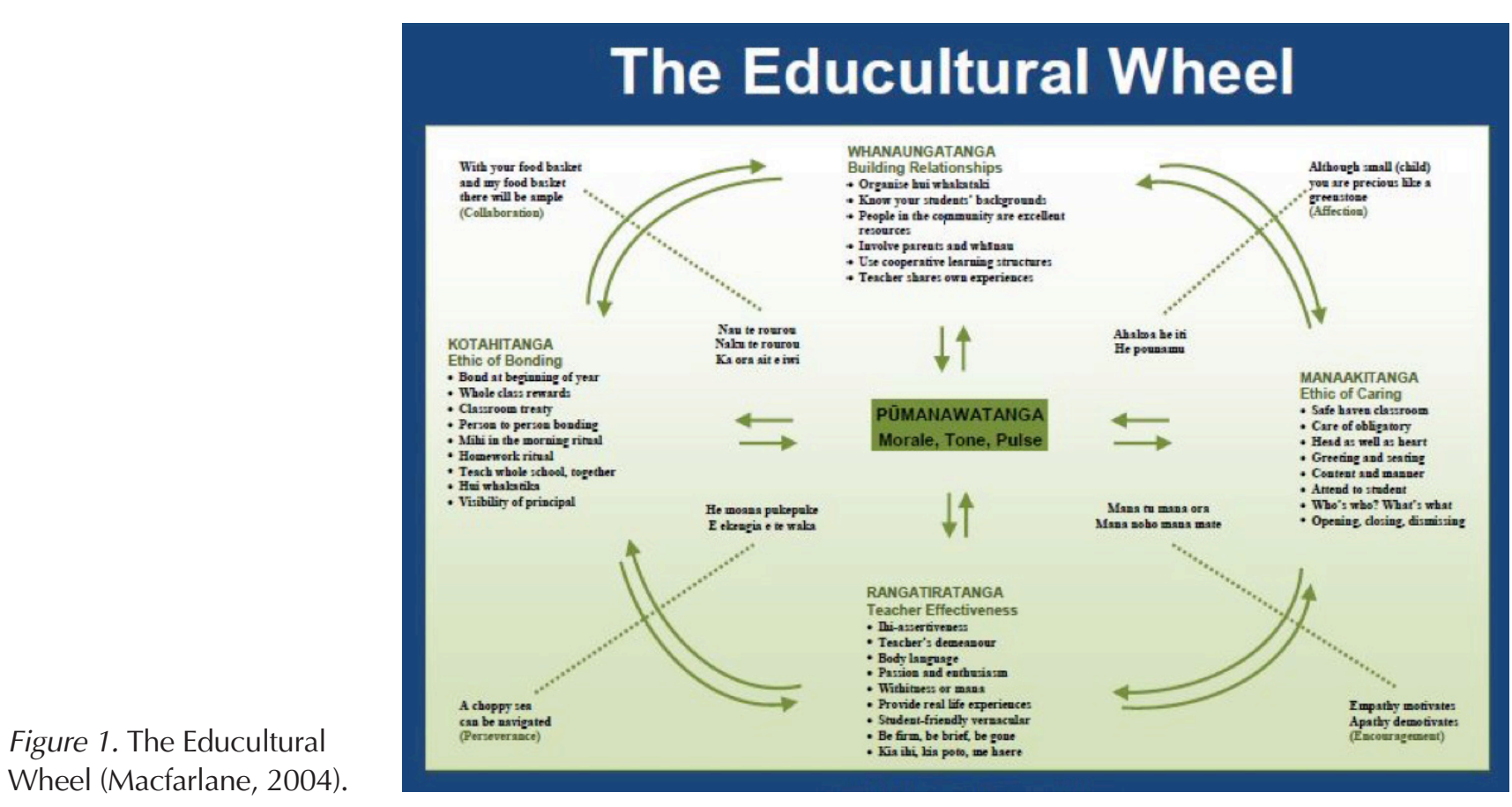




\section{METHODOLOGY: THE RESEARCH DESIGN}

It is believed that hermeneutics and, in particular, Gadamer's hermeneutic circle, provide a useful research strategy by seeking to understand the whole through reference to individual parts and vice versa (Gadamer, 2001). This approach assists in unpacking the complexities of kaupapa Māori understandings of inter-relatedness. Hermeneutic enquiry (which involves dialogue and iterative engagement over time), it is believed, may provide a process to explore kaupapa Māori concepts of empathy and classroom social interaction (Walshaw \& Duncan, 2015).

This study used a hermeneutic research approach, guided by the seminal work of Gadamer (1975), and others who followed, which supported the use of an interpretive research strategy. The hermeneutic approach enabled participants to build their understandings of separate parts to comprehend the notion of a collective (the whole) over time, with iterative dialogue between the researcher and participants (Charmaz, 2003; Dostal, 2002; Gadamer, 1975, 2001). This approach aligned with Māori contentions of inter-relatedness and was culturally-responsive in further ways. The participants were actively engaged in the research process and were given the autonomy to coconstruct their own understandings within the partnership rather than be subordinate to the research process or researcher (Smith, 2012). The objective was to undertake research with, and not on, the research participants (Herda, 1999).

The research was conducted using a single case study design, based within a classroom setting in a low socio-economic, culturally diverse, Year 9-13 secondary school in the city of Christchurch, New Zealand. The case study was purposely selected from Year 13 classes where the principal believed effective social/relational interaction was occurring. The case study involved a Year 13 class (students aged 16-18 years) and their teacher. Three students and the teacher identified as Māori. The Board of Trustees, principal, teacher and students were provided with information letters and consent forms as part of the University of Canterbury Human Ethics consent application process. Confidentiality of data was ensured through research participants receiving personalised transcriptions, the use of pseudonyms in reporting, as well as personal details and transcripts being held in a passwordprotected and secure location.

Initially, one-on-one interviews were undertaken with 14 students (three male, 11 female) and their teacher. Semi-structured interviews explored research participants' experiences and understandings of empathy within their classroom. The interviews were recorded and transcribed, and the typed transcripts were returned to the research participants to be checked for accuracy. The transcripts were then uploaded into the $\mathrm{NVivo} \circledast$ data analysis software. The NVivo® software enabled the organisation of the large quantity of qualitative data and subsequent thematic coding of that data into increasingly finergrained data sets (Ozkan, 2004). Previously identified (Western) manifestations of empathy within learning and teaching contexts were used to identify and group the students' and teacher's experiences of empathy within this particular learning context (Duncan, 2011; Rogers, 1977; Rogers \& Freiberg, 1994). These data sets were then used to develop key discussion points for a subsequent focus-group interview with the students, and another one-onone interview with the teacher. The focus-group interview enabled participants to re-engage with themes that emerged from the initial one-on-one interviews, providing the opportunity for research participants to explore these themes at a greater depth of understanding through discussion with other participants. The focus-group interview and teacher interview were recorded and once again transcribed, with the transcript checked by research participants and then thematically coded via NVivo $囚$. Students maintained a written diary in which they could record observations or views that they thought of after or between interviews. The diary also enabled them to record their views as and when they occurred, rather than having to wait until the interview. The teacher, too, maintained a research diary to record thoughts and observations. In addition, throughout the research, the researcher recorded observations and emerging themes. These research diary notes were all also uploaded into the NVivo ${ }^{\circ}$ software.

The research participants' experiences and observations of these (Western) manifestations were aligned by the researcher to the Educultural Wheel. The identified manifestations and their alignment with the model were validated (or not) by research participants within subsequent interviews. By employing this strategy, numerous themes were identified, analysed and reorganised into the Educultural Wheel categories that were, in turn, used to re engage research participants in deeper dialogic engagement. Factors affecting these kaupapa Māori concepts were then identified and are presented in this paper's findings. This led to the development of the final respondent-validation interview agenda and further thematic data coding and analysis.

Within the final respondent-validation interviews, research participants were asked to share a visual metaphor representing how they believed the Māori concepts of manaakitanga, 
kotahitanga, rangatiratanga, whanaungatanga and pūmanawatanga, as presented within the Educultural Wheel, gave meaning for them of relating to others. The research participants' descriptions of their visual metaphors were interpreted and recorded by the researcher while participants were developing/ drawing/describing the development of their visual metaphor. These visual metaphors and associated descriptions were validated by participants when the final respondent-validation transcripts, which included their drawings, were returned to them for checking.

The research methodology is summarised in Figure 2.

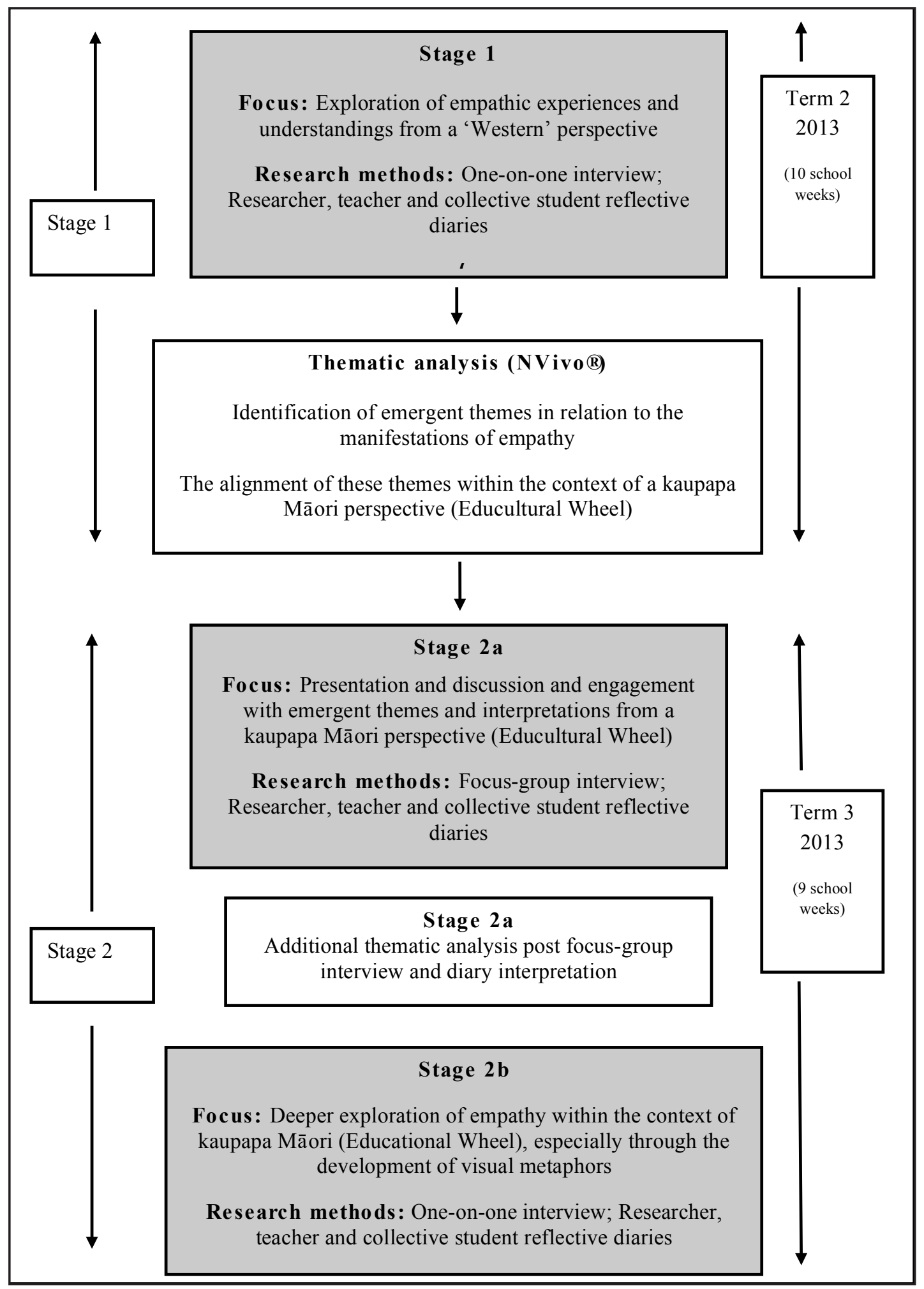

Figure 2. Outline of the research methodology. 


\section{FINDINGS (STAGE 1): WESTERN AND KAUPAPA MĀORI CONSTRUCTS ABOUT EMPATHY - SYNERGIES AND DISTINCTIVES}

The findings from this research are interpretations from participants' lived experiences, and therefore are dependent on the personal frames or histories of participants and that of the researcher (Crotty, 1998; Dostal, 2002; Guba \& Lincoln, 1989). The findings may be contextual to the setting in which they were generated. Due to the dynamics of focus-group interviews and an iterative research strategy, the understandings developed by participants emerge inter-relationally through the interactions between them (Creswell, 2002). It should be acknowledged that the understandings drawn out by the work of Duncan (2011) are not internationally recognised and, thus, interpretations made within this case study must be considered in this context.

The discussion in this section is presented under four headings (derived from the Educultural Wheel) to show synergies and distinctives between kaupapa Māori principles, Western constructs about empathy from selected literature, and the data provided by research participants. A brief description of each construct (kaupapa Māori and Western) is provided. Following that, the Stage 1 findings from the case study are presented. These findings are discussed in relation to the emerging synergies with kaupapa Māori principles, while also noting that some Māori distinctives did not explicitly emerge.

\section{Manifestations of empathy related to the ethic of relationship-building and interdependence}

The kaupapa Māori principle of whanaungatanga references the establishing of relationships in a Māori context based on kinship, common locality and common interests. Whanaungatanga involves building the framework of social groupings - such as a family (whānau) - and is facilitated through cooperative activities, shared experiences and participating in larger, external events as a group. In a school and classroom environment, teachers engage in whanaungatanga by getting to know each student as an individual, and by generating opportunities to build mutual trust and respect. Students learning about the teacher's interests and concerns is also important. Cooperative learning strategies, involving parents and families in the classroom and engaging the support of community people as resources, are all ways of building whanaungatanga.

Whanaungatanga can align with Western literature constructs of empathy such as experiencing a sense of belonging, a strengthening bond, feelings of a supportive environment, and feelings of compassion and caring.
The case study data indicated that having similar experiences, events or tasks - such as school camps or shared tragedy or challenge - had a big effect on building a strong sense of relationship. For some respondents, similar shared experiences with others enabled them to engage empathically. The increased socialisation occurring at school outdoor education camps and through cooperative learning tasks assisted this process. Socialisation beyond the classroom also assisted students in feeling part of the group. Familiarity and predictability of relationships was also seen as assisting in building empathy.

This case study occurred during the aftermath of a severe earthquake in the city of Christchurch and there were multiple references to this tragedy and the resultant challenges to family, whānau and the school. Research findings indicated that, for many, these challenges brought them closer together into more personalised interactions and, therefore, more empathic engagement, which generated a positive spiral. However, the stress associated with the earthquake appeared to have had an effect on social/ relational processes, creating a lower motivation to engage sympathetically, which hindered this positive spiral. Respondents indicated they believed that, even throughout the stress during and post this event, interpreting others was something they did involuntarily. Interpreting others empathically, they felt, just happened - even before they had a chance to think about not interpreting others. Respondents indicated they believed stress and workload had the greatest effect on their responses to empathic interpretation of others; respondents reported feeling burned-out, and felt that this inhibited their motivation to engage in an appropriate sympathetic response. They were too tired to care on occasions; they had become more 'hardened' about showing sympathy, rather than less empathic.

Cooperative approaches to tasks and socialisation beyond the classroom that made participants feel more part of the group are also implicit in whanaungatanga. Consistency and predictability in relationships also align strongly with whanaungatanga. Relationship-building characteristics, implicit in whanaungatanga, but which did not emerge from the case study, include: engaging with wider family members; connections to members of the local community, and reciprocity of sharing - for example, a teacher sharing aspects of his or her background.

\section{Manifestations of empathy related to the ethic of care}

The kaupapa Māori principle of manaakitanga embodies a type of caring that is reciprocal and 
unqualified, based on respect and kindness, and encompasses a 'duty of care' (Macfarlane, 2004). It includes the unqualified caring and respect for others and humanity, expressed through extending hospitality (offering food and refreshments), consolidating friendship, and creating safety and a sense of belonging, comfort or 'feeling at home'. Manaakitanga is reciprocal in the sense that "... there is simply faith that one day that which one has contributed will be returned" (Ritchie, 1992, p. 75). It is unqualified in the sense that "... you are obliged to support, to care for, be concerned about, to feed, shelter and nurture your kin, and especially when they are in need ..." (Ritchie, 1992, p. 78).

Manaakitanga can align with (but is not the same as) Western constructs of a supportive environment, extending compassion and caring for others.

Research findings from this case study indicated that the students and teacher believed that empathy is developed through the ethic of care and is supported when: they feel valued by others; they feel happy in the environment, and they are comfortable and trusting of others. The importance of the personalisation of the interaction was expressed strongly by students. The more interest the students felt teachers or other students took in them personally, the more they believed they experienced the ethic of care.

These findings appear to align with the kaupapa Māori principle of manaakitanga. Empathy was associated with heightened levels of comfort, trust and feeling valued and cared for. These characteristics reflect the expressions of kindness, safety and sense of belonging inherent in manaakitanga. However, there is also added richness in the Māori expression of manaakitanga which was not emphasised in the research participants' commentaries. Examples are the development of empathy through extending hospitality, the sense of nurture and the emphasis on reciprocity and an obligatory duty of care.

\section{Manifestations of empathy related to the ethic of bonding and unity}

The kaupapa Māori principle, kotahitanga, is a concept of becoming one out of many, where a sense of unity and inclusiveness is sought by recognising everyone's mana (status, pride, honour) (Macfarlane, 2004). Kotahitanga is inclusive of individuals while developing a group dynamic. For example, in a learning environment, kotahitanga might be expressed through the development of person-toperson relationships (expressed as kanohi-ki-te-kanohi in Māori vernacular) between teacher and students, between students and students, and the use of shared experiences and activities. Macfarlane (2004) reports on several examples of how this principle translates into reality and these include: giving awards to the class as a community; engaging in rituals or routines, and forming a class treaty.

Kotahitanga can align with (but is not the same as) Western literature constructs of empathy such as: a sense of belonging or identity with a group of members within a group; feelings of a strengthening bond; a supportive environment; feeling as others feel, and the spontaneous spread of emotion.

Analysis of the case study data on the ethic of bonding indicated that the more personalised the interaction, the more predictable other interactions were, and the closer the bond became. There was a strongly-held assumption among respondents about the need for a perception of an investment in the relationship by the teacher or other student. When present, this perception enabled the bond to become closer. Data showed that the more personalised the interaction, the more accurate the empathic interpretations and, therefore, the stronger the bond. Participants also indicated that they felt their motivation to engage in empathic interpretation of others was motivated by a desire to belong to a group or to avoid a negative emotional response as a result of incorrectly interpreting others' feelings or intentions. A contention is that 'feeling as others feel' may help students avoid negative physical, emotional or social experiences from misinterpretation of others as the result of misreading a social situation.

The case study findings show some synergy with the kaupapa Māori principle of kotahitanga. Belonging to a bigger group was important to participants, while individualised, personal interaction was critical to that 'belongingness' occurring. Elements such as predictability and being correctly interpreted enabled group bonding to occur. This can align with kotahitanga characteristics of building group dynamics while including individuals and recognising their mana (earned respect). Through the expression of kotahitanga, rituals and routines allowed the predictability and consistent interpretation of behaviour which was emphasised by participants. Students identified the positive role of the teacher in facilitating both an ethic of care in the classroom and their own visibility. Often, the teacher just being there gave the students a sense of security. The whakatauki (proverb), 'Ehara taku toa i te toa takitahi, engari he toa takitini' (which translates as 'succeeding not individually but collectively'), has relevance in the domain of kotahitanga. Studies of effective schools and classrooms have consistently drawn attention to 
the importance of strong educational leadership. According to Hargreaves and Fink (2006), one of the more difficult dimensions of leadership is the part that provokes teachers to look beyond their own classrooms and themselves. Aspects of kotahitanga that did not emerge in the findings were a sense of the importance of the wider group (that is, the whole class), and the use of class treaties or commitments.

\section{Manifestations of empathy related to autonomy, leadership, teacher effectiveness}

The kaupapa Māori concept of rangatiratanga (autonomy, leadership, teacher effectiveness) relates to the expression ihi (confidence, assertiveness) and, in this context, it relates to a person's mana, their chiefly presence (body language), leadership, personal magnetism, their inspirational demeanour, passion and enthusiasm.

Rangatiratanga appears to align with (but is not the same as) Western constructs of empathy such as: the ability to predict the behaviour and attitude of others; compassion and caring; experiencing encouragement, and helping.

Studies of effective teachers have consistently drawn attention to the importance of strong classroom leadership, as contrary to 'control'. This is in line with Glasser's (cited in Charles, 2005) notions of 'lead teachers' as being preferred over 'boss teachers', and the Prochnow and Macfarlane (2010) descriptions of teachers being assertive and simultaneously warm.

The case study data showed that students noticed differences in the ability of teachers to interpret accurately the students' emotions and propensities. The predominant cues students used for their own interpretation of others were facial expressions, body language and tonal inflections in the person's voice. Respondents indicated they also believed that more accurate empathic interpretation is achieved through experience with individual patterns of behaviour for individuals, rather than through predetermined rules. Respondents also indicated that, when interpreting others, they felt that disturbances and stress resulted in empathic inaccuracies through the misinterpretation of cues, or from missing cues altogether. The perceived genuineness of the encouragement given was significant in building friendship and trust. Helping was experienced most where there was personal investment in the relationship. Students also commented that they believed some teachers needed to be aware of their own emotional states and to recognise that, potentially, other students were interpreting these states.

These case study findings have some multiple commonalities with the kaupapa Māori principle of rangatiratanga. Participants reported noting the body language of teachers along with facial expressions and use of tone in their voice. The enthusiasm of the teacher was identified in the participants' commentary on genuineness being associated with encouragement and building trust. The passion and inspiration of the teacher are evidenced in the amount of personal investment experienced by the student in the helping relationship. While participants did comment on the confidence and ability of their teacher to be firm and relational, they expressed the opinion that this was specific to some teachers. The data did indicate the presence of a chiefly presence or mana, but the specific use of these terms to identify these characteristics did not emerge.

\section{DISCUSSION: STAGE 1}

The Stage 1 data on empathy from the case study participants shows some commonality between their understanding of empathy and the kaupapa Māori principles (and strategies) as described in the Educultural Wheel (Macfarlane, 2004). However, there are also distinctive themes within the Educultural Wheel which did not emerge in participant commentary, such as whole-class rewards. It is likely that many of these distinctives were simply outside of the participants' experience of developing or describing classroom empathy, rather than being a concept that either they could not grasp or thought did not develop empathy.

Stage 2 of the research, where Māori (4) and nonMāori (11) participants were given the opportunity to engage with the kaupapa Māori principles expressed in the Educultural Wheel, created an opportunity to test this thinking.

\section{FINDINGS (STAGE 2): PARTICIPANT ENGAGEMENT WITH THE KAUPAPA MĀORI PRINCIPLES EXPRESSED IN THE EDUCULTURAL WHEEL}

In Stage 2, participants were asked to share a visual metaphor representing how they believed kaupapa Māori concepts of manaakitanga, kotahitanga, rangatiratanga, whanaungatanga and pūmanawatanga related to, and may or may not contribute to, the facilitation of empathic interaction.

All the participants indicated that they believed these concepts contributed to the facilitation of empathic interaction. They all also indicated that they felt these concepts provided a useful framework to share their understandings of empathy. This was evident when observing the ease with which the participants were able to develop their visual metaphors of how these kaupapa Māori concepts related. Of further interest was the ease with which participants were able to integrate their own 
histories, traditions and cultural backgrounds within these kaupapa Māori concepts.

The visual metaphors provide a window into participants' understandings of empathy from a generalist (Western conventions perspective) and a culturalist (kaupapa Māori perspective). The following section uses four selected (there were 10) diagrams to show the participants' responses to, and understandings of, manaakitanga, kotahitanga, rangatiratanga, whanaungatanga and pūmanawatanga after engaging in the research process. It is proposed that these visual metaphors demonstrate a wide range of deeper understandings of a kaupapa Māori perspective and that their inclusion is important within the findings.

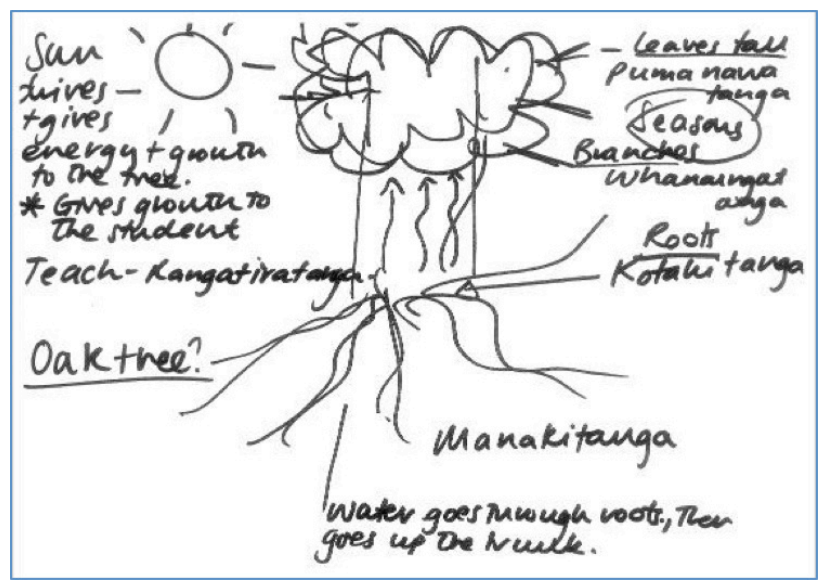

Figure 3. The Wise Oak Tree.

(Drawing and text developed by Participant 11, 24 September 2013)

Respondent Description: Empathising is all about being able to draw water up to nourish the leaves. The ethic of care or Manaakitanga forms the foundation for this model through the roots. This ethic of care is spread out in the soil in a fine network of roots to soak up the moisture. From there it is the larger roots and trunk that is bonding or Kotahitanga - that draws the water up to the families of branches or Whanaungatanga. It is on these Whānau that the Pūmanawatanga (fresh green leaves) grow and absorb energy from the sun or Rangatiratanga. Therefore, for this model, it is the Rangatiratanga that provides the energy. If the tone or pulse (leaves) look dead or stressed then there is not enough light from the Rangatiratanga, the Manaakitanga is not deep and dispersed enough, or there are problems with the roots trunk or branches.

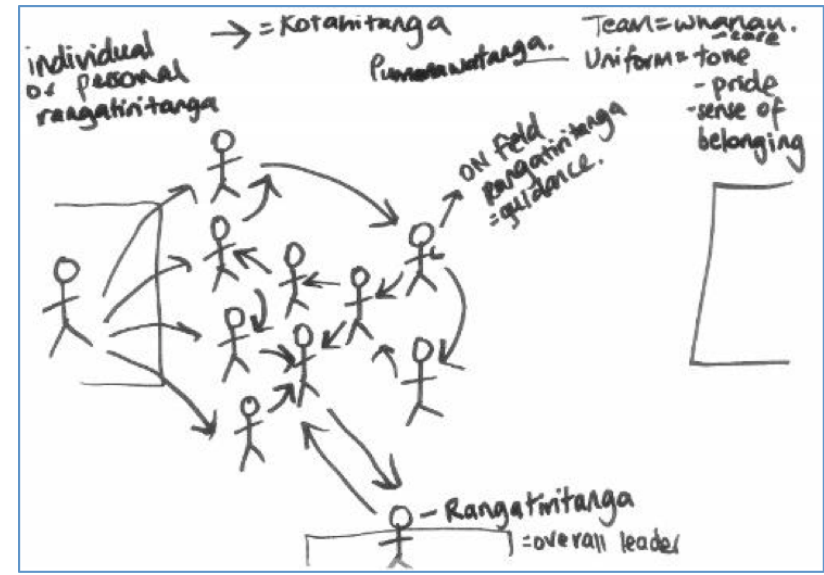

Figure 4. The Soccer Team.

(Drawing and text developed by Participant 13, 25 September 2013)

Respondent Description: Although the overall Rangatiratanga is the coach, there is also distributed leadership in the team with the on-field captain and senior players. The relationship/bond between the players and their motivation to understand each other's play is Kotahitanga. Whanaungatanga is represented by the overall team and groups within the team such as the forwards and the backs. In this model, the ethic of care or Manaakitanga is the team spirit or shared motivation to win. It is by the team strip or dress that the team shows the tone or pulse of the team, the Pūmanawatanga (a professional playing strip). Although the team is guided by the Rangatiratanga, each member of the Whānau is a leader in some respect to ensure the success of the team.

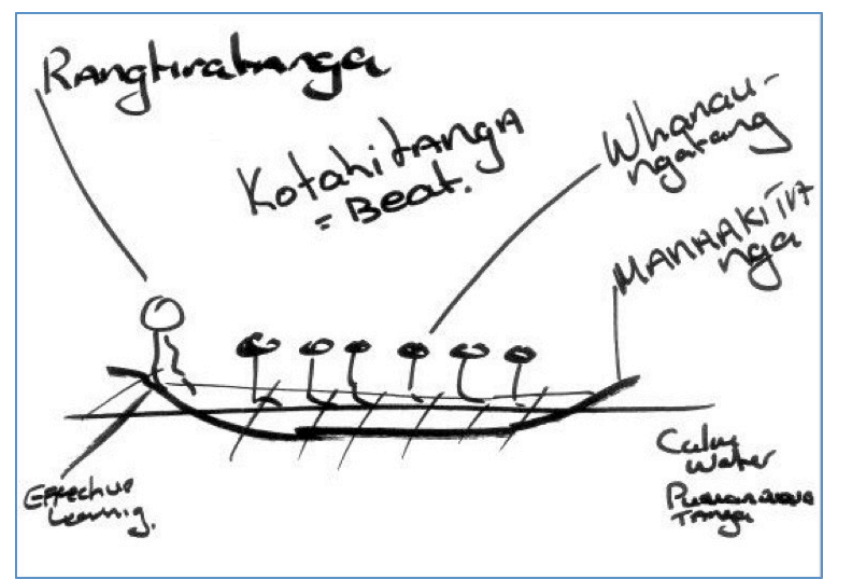

Figure 5. The Waka.

(Drawing and text developed by Participant 2, 4 September 2013)

Respondent Description: Care for those paddling the Waka is provided by the Waka itself. It is the rhythm or beat of the paddling that is the ethic of bonding or the Kotahitanga. Effective leadership is provided by the Rangatira who is steering the Waka. 
Whanaungatanga are the crew and their relationship as a Whānau. The calmness of the water represents the Pūmanawatanga or the tone or pulse.

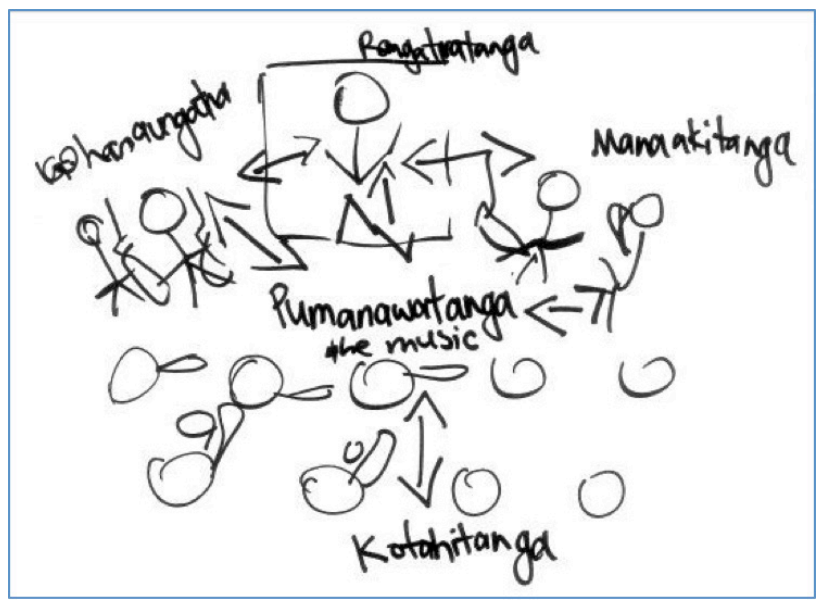

Figure 5. The Orchestra.

(Drawing and text developed by Participant 7, 24 September 2013)

Respondent Description: The conductor (Rangatiratanga) conducts (Whanaungatanga) groups within the orchestra. Each of the musicians needs to develop relationships between their own instrument and other player/s instruments as represented by Kotahitanga. There needs to be an ethic of care (Manaakitanga) or interest about working together for the ultimate outcome, the music. The quality of this music is measured by the sound or the tone, therefore Pümanawatanga really tells how well the orchestra is working as a Whānau. Rather than Pūmanawatanga creating a culture of care and ethic of bonding, it is successful bonds, care and chiefly control that lead to the establishment of Pūmanawatanga.

\section{DISCUSSION: STAGE 2}

Participants' diagrams from Stage 2 appear to indicate that the students were able to make clear associations with the kaupapa Māori principles as expressed in the Educultural Wheel. The associations were innovative and thought-provoking. The selected examples outlined above also appear to illustrate and discuss how empathy may be developed through the kaupapa Māori concepts and show that students acquired a grasp of the principles themselves.

Individual diagrams further demonstrate an understanding of cultural concepts. Figure 3, the Wise Oak Tree, brought out the richness of manaakitanga - nurture and care. A further diagram, the Pyramid (not shown for reasons of space), also focussed on manaakitanga, highlighting "the large stable foundation" it provides to build the other qualities needed. Figure 4, the Soccer Team, brought out wisdom around the varied roles and uses of rangatiratanga. Figure 5, the Waka, makes kotahitanga central through the emphasis on the rhythm or timing used to paddle the waka. Finally, Figure 6, the Orchestra, commented that the pūmanawatanga, the tone or pulse of the group, cannot just be invoked; rather, it has to be built up through the ethics of care, bonding and leadership. A breadth and depth of understanding about group dynamics and how empathy develops are revealed through the diagrams. The diagrams also show keen insights into how it is that the interconnections of multiple factors together enable empathy to become the tone or pulse of a group.

The Stage 1 commentary on empathy by case study participants showed areas of convergence between Western and Māori principles. However, that commentary left out some elements inherent in the kaupapa Māori principles and focussed less on interconnections that promote empathy in a group. The visual metaphors used in Stage 2 of the research showed the understandings participants had made with regards to traditional Māori insights about empathy. Some cultural distinctives which did not emerge in the Stage 1 data were apparent in the visual metaphors. This suggests that some distinctives were simply initially outside of the participants' experience of developing or describing classroom empathy, rather than being concepts that were irrelevant or inconsistent with their awareness of group relationships.

Through engaging with the Educultural Wheel, research participants appear to have been able to express richer and broader ideas about empathy. Importantly, this included the ability to show awareness of the inter-relatedness of the parts which work together to bring empathy to a group of people; in this case, a class of students and their teacher.

\section{CONCLUSION}

In this case study, the Educultural Wheel appeared to enhance awareness about the social and relational development of empathy, regardless of the ethnicity of the participants. For broader contexts, it seems reasonable to assume that the Educultural Wheel would have the resonance and breadth to bring more deep-rooted understandings of the development of empathy (manaakitanga) to enhance the learning environment for all learners and teachers.

Research suggests the need for teachers and school leaders to consider with more earnestness the voices and thinking of their students, given that they are considered to be the most discerning consumers of education. The lack of knowledge and awareness that many teachers may have about the cultural meanings 
residing in Māori students raises important questions for equity and democracy.

Banks (2004) introduced five dimensions for the cultural enhancement of education: content integration; knowledge construction; equity pedagogy; prejudice reduction, and empowering school culture. Although the five dimensions of multicultural education are highly inter-related, each requires deliberate attention and focus. This study enabled an interaction with, in particular, the first two dimensions, in a simple way. Content integration deals with the extent to which teachers use examples and content from a variety of cultures and groups to illustrate key concepts, generalisations and issues within their subject areas or disciplines. The knowledge construction process describes how teachers help students to understand, investigate and determine how the biases, frames of reference and perspectives within a discipline influence the ways in which knowledge is constructed within that discipline. Students also learn how to build knowledge themselves in this dimension.

The exercises carried out in this research project adopted a recognised Māori cultural framework the Educultural Wheel - to explore, explain and discuss the meanings that secondary students may derive from some of the quintessential concepts that operationalise the Māori world.

\section{REFERENCES}

Banks, J. A. (2004). Teaching for social justice, diversity, and citizenship in a global world. The Educational Forum, 68, 289-298.

Bishop, R., Berryman, M., \& Wearmouth, J. (2014). Te kotahitanga: Towards effective education reform for indigenous and other minoritised students. Wellington, NZ: NZCER Press.

Castagno, A. E., \& Brayboy, B. M. J. (2008). Culturally responsive schooling for indigenous youth: $A$ review of the literature. Review of Educational Research, 78(4), 941-993.

Charles, C. M. (2005). Building classroom discipline. Boston, MA: Pearson.

Charmaz, K. (2003). Grounded theory: Objectivist and constructivist methods. In N. K. Denzin \& Y. S. Lincoln (Eds.), Strategies of qualitative inquiry (2nd ed.), (pp. 249 -291). Thousand Oaks, CA: SAGE.

Creswell, J. W. (2002). Research design: Qualitative, quantitative, and mixed methods approaches. Thousand Oaks, CA: Sage Publications.

Crotty, M. (1998). The foundations of social research:
Meaning and perspective in research process. Crows Nest, Australia: Allen and Unwin.

Dostal, R. J. (Ed.). (2002). The Cambridge companion to Gadamer. Cambridge, UK: Cambridge University Press.

Duncan, W. (2011). Understanding the nature and function of empathy in synchronous multimedia conferencing (Unpublished doctoral thesis). Massey University, Manawatu, New Zealand.

Durie, M. (1984). Te taha hinengaro: An integrated approach to mental health. Community Mental Health in New Zealand, 1(1), 4-11.

Durie, M. (1994). Whaiora: Māori health development. Auckland, NZ: Oxford University Press.

Gadamer, H. G. (1975). Truth and method. London, UK: Sheed and Ward.

Gadamer, H. G. (2001). The beginning of knowledge. New York, NY: Continuum.

Guba, E. G., \& Lincoln, Y. S. (1989). Fourth generation evaluation. Newbury Park, CA: SAGE.

Hargreaves, A., \& Fink, D. (2006). Sustainable leadership. San Francisco, CA: Jossey-Bass.

Herda, E. A. (1999). Research conversations and narrative: A critical hermeneutic orientation in participatory inquiry. London, UK: Praeger.

Ickes, W. (1997). Empathic accuracy. New York, NY: The Guilford Press.

Macfarlane, A. (2004). Kia hiwa rā! Listen to culture: Māori students' plea to educators. Wellington, NZ: NZCER Press.

Macfarlane, A., Cavanagh, T., Glynn, T., \& Bateman, S. (2007). Creating culturally safe schools for Māori students. Australian Journal of Indigenous Education, 36, 65-76.

Ozkan, B. C. (2004). Using NVivo to analyse qualitative classroom data on constructivist learning environments. The Qualitative Report, 9(4). Retrieved from: www.nova.edu/ssss/QR/QR9-4/ozkan.pdf

Pere, R. (1991). Te wheke: A celebration of infinite wisdom. Gisborne, NZ: Ao Ako Global Learning New Zealand Limited.

Prochnow. J., \& Macfarlane, A. (2010). Managing classroom behaviour: Assertiveness and warmth. In C. Rubie-Davies (Ed.), Educational psychology: Concepts, research and challenges (pp. 150-166). London, UK: Routledge. 
Rogers, C. R. (1977). Carl Rogers on personal power. New York, NY: Delacorte Press.

Rogers, C. R., \& Freiberg, H. J. (1994). Freedom to learn (3rd ed.). Columbus, $\mathrm{OH}$ : Merrill.

Ritchie, J. (1992). Becoming bicultural. Wellington, NZ: Huia Publishers.

Smith, L. T. (2012). Decolonizing methodologies: Research and indigenous peoples. London, UK: Zed Books.

Walshaw, M., \& Duncan, W. (2015). Hermeneutics as a means to understand empathy in on line learning environments. International Journal of Research and Method in Education, 38(3), 304-319.

\section{AUTHOR PROFILES}

\section{Dr Wayne Duncan}

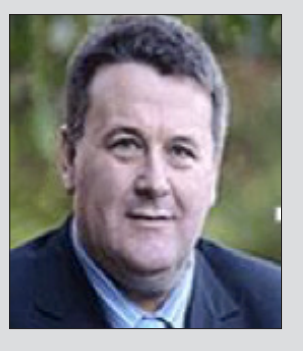

Wayne Duncan is a deputy principal at Northern Southland College, Lumsden, New Zealand. His research work focuses on empathy within learning and teaching environments. His doctoral research focused on understanding the nature and function of empathy within synchronous multimedia conferencing. This report formed an outcome of a research grant from the Nuthall Trust.

Email:wduncan@nsc.school.nz

$$
\text { Dr Angus Macfarlane }
$$

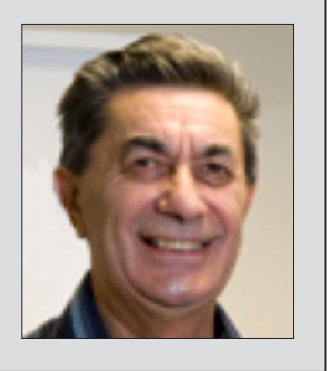

Angus Macfarlane (Ngāti Whakāue) is Professor of Māori Research at the University of Canterbury, New Zealand. He has published seven books and has been the recipient of prestigious awards for his academic achievements and contributions to Māori education. His research explores cultural concepts and strategies that influence professional practice.

Email: angus.macfarlane@canterbury.ac.nz

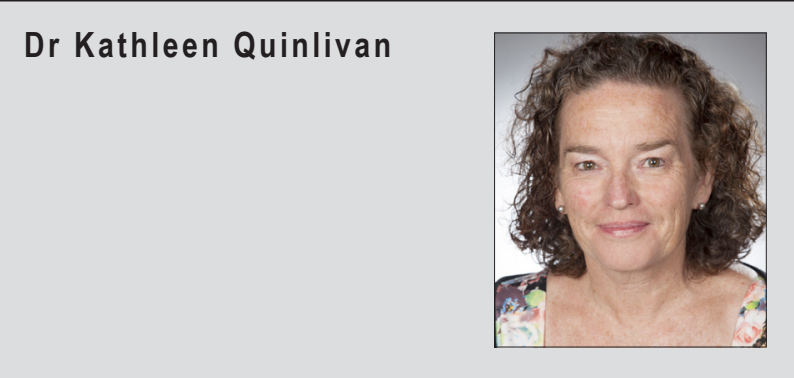

Kathleen Quinlivan is an associate professor in the School of Educational Studies and Leadership in the College of Education, Health and Human Development at the University of Canterbury. She researches and writes in the field on critical sexuality education studies, with a particular focus on school-based sexuality education programmes, and how they can more actively engage with the sexuality, gender and race politics of diverse young people's lives. She puts contemporary theory to work in order to reconceptualise the epistemological and pedagogical implications of this project.

Email: kathleen.quinlivan@canterbury.ac.nz

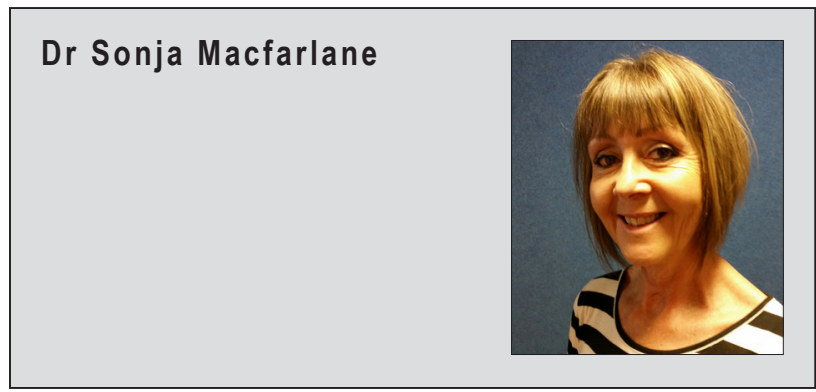

Sonja Macfarlane (Ngāi Tahu; Ngāti Waewae) is an Associate Professor at the University of Waikato, New Zealand. Her work focuses on Māori education, and developmental and cultural psychology. Her research explores culturally-responsive evidence based practices that enhance the social, cultural and educational outcomes achieved by Māori learners.

Email: sonjamac@waikato.ac.nz 